\title{
Multilevel Diffuser Augmented for Horizontal Axis Wind Turbine
}

\author{
Fariz Qashidi Putra ${ }^{1}$, Dani Rifai $^{1}$, Kutut Suryopratomo ${ }^{1, *}$, and Rachmawan Budiarto ${ }^{1}$ \\ ${ }^{1}$ Departement of Nuclear Engineering and Engineering Physics, Universitas Gadjah Mada, Indonesia
}

\begin{abstract}
Indonesia is an area with the low and fluctuating wind speed. Therefore, the implementation of the wind turbine to generate electricity become ineffective and economically unprofitable. Diffuser Augmented Wind Turbine (DAWT) is the augmentation technology in wind turbine which could increase wind speed flow that arrives on the turbine blade. The working principle of the diffuser is to create a difference in pressure inside and outside the diffuser. The pressure inside the diffuser is lower than the pressure outside so that the wind will be accelerated into the diffuser and wind speed will dramatically increase at the inlet of the diffuser. This study will be presenting a modified design of diffuser augmented wind turbine (DAWT) by designing multilevel diffuser with additional inlet curvature and flange. This research aims to evaluate the amplification of flow velocity profile around the diffuser that has been engineered. The numerical study is performed using computational fluid dynamic (CFD) to obtain the highest ratio of speed increment. The verification of numerical initial condition is validated by comparing the result of validation with experimental data available in the literature. The result shows that a ratio of increase in speed is 2.08 times higher than conventional wind turbine over $4 \mathrm{~m} / \mathrm{s}$ inlet velocity. In the equation of a wind power output, the wind speed is proportional to the cubic power of its wind power output. Therefore, the utilization of dual-stage diffuser device in wind turbine would give significant increment on the power output of wind turbine.
\end{abstract}

\section{Introduction}

Indonesia, as a developing nation, still depends on fossil energy to fulfill almost the whole need of national energy. In 2025, Indonesian Government has several regulations in terms of reducing the use of fossil energy and supporting renewable energy development such as wind energy, solar energy, geothermal energy, ocean energy and bioenergy. Geographically, Indonesia is surrounded by two continents and has the second longest the coastal line in the world. As a result, lots of area with a high intensity of wind located in Indonesia definitely. Moreover, wind energy has certain utilization to generate electricity by using wind turbine. Unfortunately, recent research and study which is conducted by Lembaga Penerbangan dan Antariksa Nasional (LAPAN) proved that the development of wind energy technologies in Indonesia facing some vital obstacles that block the development and people's interest in exploiting wind energy as an electricity generator, such as low-speed wind velocity distribution in Indonesia at around $2.5-6 \mathrm{~m} / \mathrm{s}$ which is under cut-in speed specification for most wind turbines and huge fluctuation wind velocity in Indonesia not only in speed degree but also in quantity degree. One of technology that can be applied is with the additional shrouded wind turbine or Diffuser-Augmented Wind Turbine (DAWT).

The diffuser is an additional device of wind turbine that would increase wind speed when the wind comes into the wind turbine. Principal work of diffuser is to make a pressure difference between its inlet and outlet. Inlet pressure lower than outlet pressure, so that the wind speed being accelerated into the diffuser and the wind speed would increase enormously in an inlet. The use of flanged diffuser produces low-pressure area in an outlet because of the existence of vortex formation and draw more a lot of mass flow into diffuser [1], [2]. Furthermore, the utilization of diffuser with inlet curve could ease the wind to flow into the diffuser and will create streamline from wind flow [3]. The research about wind turbine was started from 1920 by Alexander Betz. This research was reviewed by Sanuki (1950), Iwasaki (1950), Lilley and Rainbird (1956), Kogan and Seginer (1963), Gilbert et al. (1978), Gilbert and Foreman (1983), and Igra (1981). The next research still uses diffuser structure which is cover the wind turbine with additional features in the form flanged on the outlet sides. The research about diffuser design was being conducted by Matsushima et al. (2006), Abe and Ohya (2004), and Ohya \& Karasudani (2010).

Several ways have already conducted to upgrade the power produced by a wind turbine in low wind velocity area, such as by undertaking modification to the wind turbine on its rotor and diffuser (Kosasih, 2012). Another possible approximation is manipulating the wind velocity so that local velocity in the inlet of a wind turbine would be higher [4].

Ohya et al. were comparing three different types of hollow structures that might be installed in wind turbine. Those are a nozzle, cylindrical and diffuser (Fig. 1). It was found that an enormous increase in wind speed was

\footnotetext{
* Corresponding author: kutut@ugm.ac.id
} 
obtained by diffuser type. Afterward, the diffuser had been engineered by adding several parameters such as the angle of inlet shroud opening, hub ratio, the height of flanged, inlet curvature, and center body length. The height of flanged in the diffuser was being variated with diffuser's diameter (h/D). The experiment result showed that the power of wind turbine with diffuser had enhanced up to 4-5 times more than the conventional one. The specifications of diffuser prototype (class of $500 \mathrm{~W}$ ) are L $=1.25 \mathrm{D}, \mathrm{D}=0.72$ metres, $\mathrm{h}=0.5 \mathrm{D}$ and the diameter of rotor is 0.7 metres.

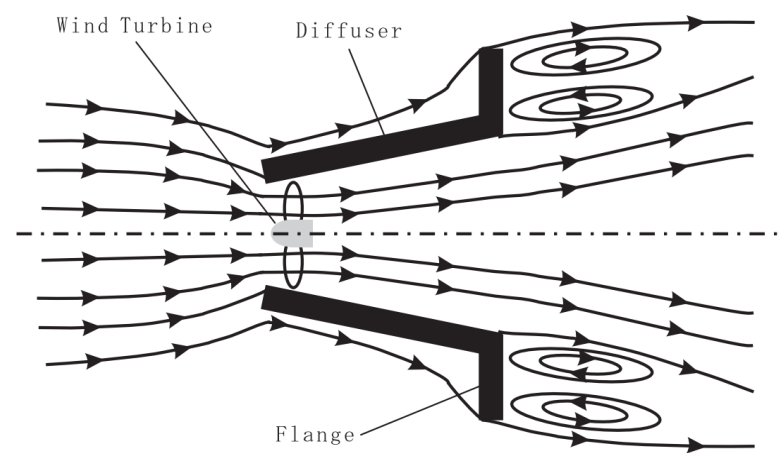

Fig. 1. Schematic view of flow mechanism around a flanged diffuser (Abe \&Ohya, 2004).

Optimization of Diffuser Augmented Wind Turbine (DAWT) was conducted by Kannan et al. [5]. The study was comparing four design of diffusers by using ANSYS Fluent. The best diffuser generates local wind velocity of $61.25 \%$ increment that of the approaching wind speed. It has 160 of diffuser opening angle with the addition of splitter inside the diffuser. The length and the opening angle of the splitter are 0.5 meters and 40 respectively.

Tito et al. [6] were discussing the effect a variation of flange angle on diffuser DAWT performances using CFD. The existence of flanged caused the vortex formation at back side of the flange. Quantitative data showed flow performance in an interior diffuser with top increased velocity augmentation of the flanged diffuser is angle $90^{\circ}$ by $9.82 \mathrm{~m} / \mathrm{s}$ or 1.96 times freestream wind velocity with $\mathrm{L} / \mathrm{D}$ ratio for about 7.7 .

In the equation of a wind power output, the wind speed is proportional to the cube (n3) of a wind power output. If we could increase the wind speed by exploiting the fluid dynamic nature around a structure or topography, the power output of a wind turbine can be increased substantially.

Thus, in the present work, carries out a study using Computational Fluid Dynamics (CFD) to assess the effect of the velocity speed-up ratio inside the diffuser. This simulation emphasizes the geometric design of stage diffuser development which has the highest of ratio increase in speed.

\section{Methodology}

The study was performed using CFD numerical simulation methods. By definition, CFD is a focused study that might predict a fluid flow, heat transfer, chemical reactions, and other phenomena by completing mathematical equations numerically. One advantage of using CFD is able to conduct experimental and analytical approach [7]. Numerical simulations were performed on a multilevel diffuser assumed without using a rotor. It aims to obtain a position with a leverage ratio of maximum speed $\left(\left(U_{\max } / U_{0}\right)\right.$ that could be used as a reference position for laying the rotor inside the diffuser.

\subsection{Numerical Condition}

This study was using a numerical method that is used to correspond to the finite volume method (FVM), using ANSYS 17.0 Student Version software. ReynoldAveraged Navier-Stokes (RANS) equation is used as a solution. In general, RANS equation for the steady state and incompressible turbulent flow, so that the equation for conservation mass and momentum are:

$$
\begin{gathered}
\frac{\partial U_{i}}{\partial x_{i}}=0 \\
U_{j} \frac{\partial U_{i}}{\partial x_{j}}=-\frac{1}{\rho} \frac{\partial P}{\partial x_{i}}+\frac{\partial}{\partial x_{j}}\left\{v\left(\frac{\partial U_{i}}{\partial x_{j}}+\frac{\partial U_{i}}{\partial x_{i}}\right)-\overline{u_{\imath}{ }_{\imath} u^{\prime}}\right\} \\
+F_{i}
\end{gathered}
$$

with $\rho, P, U_{i}, u_{i}$ and $v$ are represented density, average static pressure, average velocity, turbulent fluctuation, and kinematic viscosity respectively. $F_{i}$ is the expression body-force which is represented a load [1]. In this research, the simulation was done without considering the rotor, so that $F_{i}=0$. It aims to get a position at a maximum ratio increase in speed as a reference for placing the rotor. The quantity $-\overline{u_{\imath}^{\prime} u_{j}^{\prime}}$ is known as Reynolds Stress Tensor or Reynolds-averaged value.

\subsection{Geometry and Computational Condition}

The simulation is used a fluid material such as air at the temperature of $27^{\circ} \mathrm{C}$ (Table 1). The study sets the flow as axisymmetric steady flow, the segregated solver is proposed, and velocity formulation is absolute whereas the turbulence model used based on the result from validation process. The boundary conditions that are used in the validation phase numerical model could be seen in Table 2. The solution algorithm uses SIMPLE (semiimplicit method for pressure linked-equation) with Second Order Upwind scheme for turbulent parameter and Second Order for the pressure with $10^{-5}$ of the convergence criterion. The solver that being used is pressure-based and steady.

Table 1. Air properties at $27^{\circ} \mathrm{C}$

\begin{tabular}{|c|c|}
\hline Property & Value \\
\hline Density $(\rho)$ & $1,1765 \mathrm{~kg} / \mathrm{m}^{3}$ \\
\hline Dynamic Viscosity $(\mu)$ & $1,8538 \times 10^{-5} \mathrm{~kg} / \mathrm{m}-\mathrm{s}$ \\
\hline
\end{tabular}


Table 2. Properties boundary condition of simulation

\begin{tabular}{|c|c|c|}
\hline $\begin{array}{c}\text { Boundary } \\
\text { Condition }\end{array}$ & $\begin{array}{c}\text { Dimension } \\
\text { (m) }\end{array}$ & $\begin{array}{c}\text { Type of } \\
\text { Boundary } \\
\text { Condition }\end{array}$ \\
\hline Left & 2.0 & Velocity-inlet \\
\hline Right & 2.0 & Pressure-outlet \\
\hline Bottom & 3.0 & Axis \\
\hline Top & 3.0 & Wall (no-slip) \\
\hline
\end{tabular}

To validate the model, we were used the geometry of diffuser proposed by Abe and Ohya (2004) (see Fig. 2). The diameter at the inlet diffuser $(D)$ is $0.20 \mathrm{~m}$, diffuser opening angle $(\phi)$ is $4^{\circ}$ and the free stream velocity $\left(U_{0}\right)$ is $5 \mathrm{~m} / \mathrm{s}$. As we could see in Fig. 2 and Fig. 3, the CFD simulation performed with a $2 \mathrm{D}$ axisymmetric assumption so that the diffuser design is being designed along the center line only. Axisymmetric has the ability to describe the modeling of a 3D object in rotational symmetry.

The computational condition for diffuser model research exists on Fig. 4 and Fig. 5. The symbol $D, h, \theta$, dan $L$ represent diameter size of inlet diffuser, the height of flange, angle of the diffuser, and diffuser length respectively, while subscript 1 and 2 are represented first stage diffuser and second stage diffuser respectively. A model is built with a diameter of inlet diffuser (D) and flange height $(\mathrm{h})$ are $20 \mathrm{~cm}$ and $0.5 \mathrm{D}$ respectively. The opening angle of the first diffuser, the opening angle of second diffuser, the length of the first and second diffuser are $40,80,0.25 \mathrm{D}$ and $1.25 \mathrm{D}$ respectively.

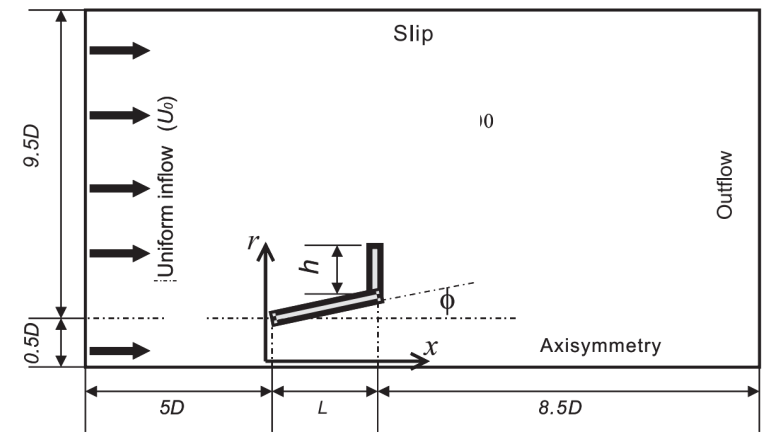

Fig. 2. Geometry and computational conditions (Abe and Ohya, 2004) for validation.

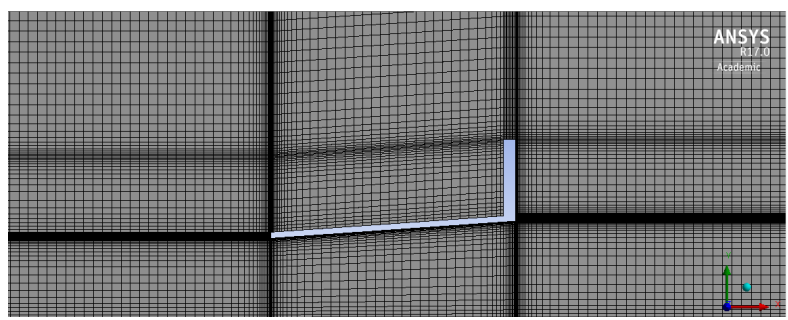

Fig. 3. The result of meshing process of diffuser model by Abe \& Ohya (2004) for validation.



Fig. 4. Geometry and computational conditions of multilevel diffuser

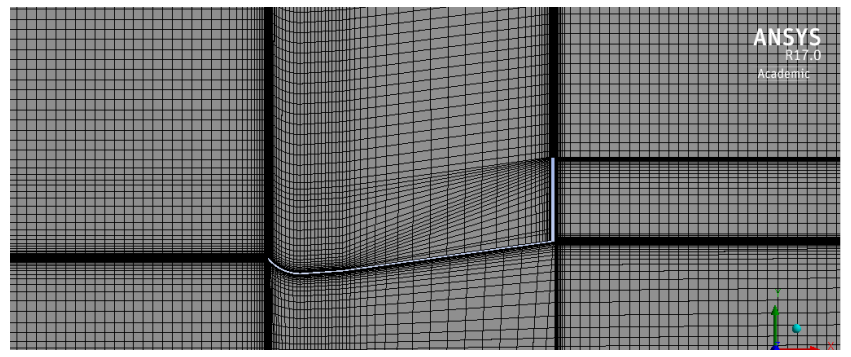

Fig. 5. The result of meshing process of the multilevel diffuser.

\section{Result And Discussion}

\subsection{Validation of Numerical Model}

Validation is used to obtain a numerical model that will be used as a reference in the simulation model of research in order to get the accurate results. Validation is done by using secondary data. The results of the validation are tried to approach the experimental results of research diffuser by Abe \& Ohya [2] as close as possible. Validation results are shown in Fig. 6. $X / D$ is the ratio of the diameter inlet diffuser and position, $U / U_{o}$ is the speed ratio distribution along the axis and $U_{\max } / U_{o}$ is the ratio of the highest speed on axis $\left(U_{\max }\right)$ with velocity freestream $\left(U_{0}\right)$, as seen in Table 3 .

Table 3. Comparison of $U_{\max } / U_{0}$ values of the results of validation and secondary data [1]

\begin{tabular}{|l|c|c|c|}
\hline $\begin{array}{c}\text { Turbulence } \\
\text { Models }\end{array}$ & $\begin{array}{c}\text { The results of } \\
\text { Validation } \\
\left(\mathrm{U}_{\max } / \mathrm{U}_{0}\right)\end{array}$ & $\begin{array}{c}\text { Abe \& Ohya } \\
\text { Experiment } \\
{ }^{[1]} \\
\left(\mathrm{U}_{\max } / \mathrm{U}_{0}\right)\end{array}$ & $\begin{array}{c}\text { Relative } \\
\text { Error }\end{array}$ \\
\hline $\begin{array}{l}\text { Spallart- } \\
\text { Allmaras }\end{array}$ & 1.61 & 1.60 & $0.36 \%$ \\
\hline ske $S W F$ & 1.51 & 1.60 & $5.83 \%$ \\
\hline ske EWT & 1.53 & 1.60 & $4.24 \%$ \\
\hline rngke $S W F$ & 1.49 & 1.60 & $6.79 \%$ \\
\hline rngke $S W F$ & 1.48 & 1.60 & $7.24 \%$ \\
\hline rke SWF & 1.45 & 1.60 & $9.24 \%$ \\
\hline rke SWF & 1.47 & 1.60 & $8.42 \%$ \\
\hline skw & 1.41 & 1.60 & $11.69 \%$ \\
\hline sstkw & 1.48 & 1.60 & $7.38 \%$ \\
\hline
\end{tabular}


Fig. 6 shows that the model of turbulence of SpalartAlmaras able to approach the results of experiments conducted by Abe \& Ohya [1]. Types of solver as used in this study are pressure-based, axisymmetric and steady. Turbulence models that being tested are Spalart-Allmaras, K-epsilon standard with Standart Wall Function and Enhanced Wall Treatment, K-epsilon RNG with Standart Wall Function and Enhanced Wall Treatment, K-epsilon Realizable with Standart Wall Function and Enhanced Wall Treatment, K-omega standard and K-omega SST.

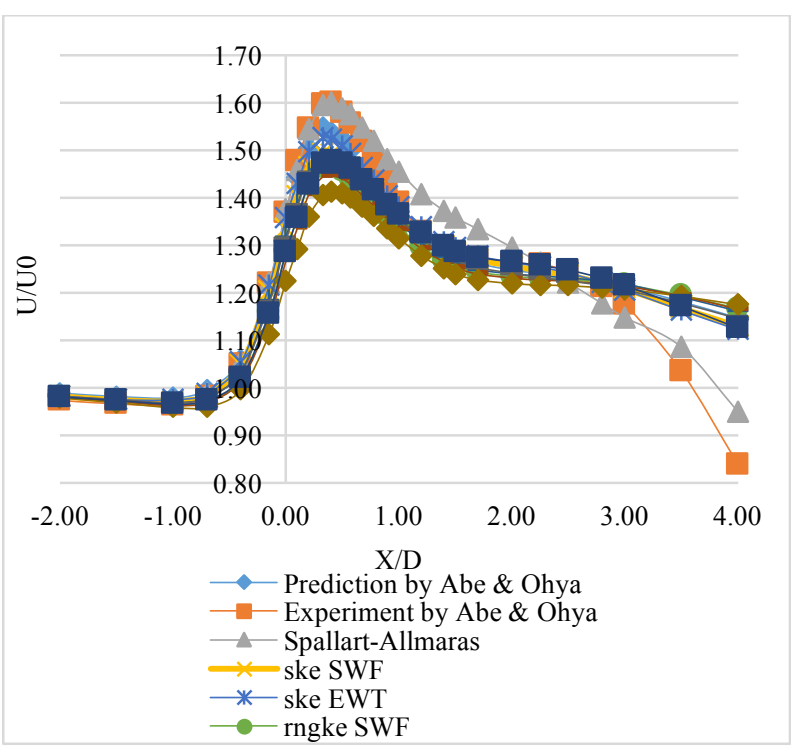

Fig. 6. The distribution of velocity ratio $\left(U / U_{0}\right)$ along the axis upon the validation of numerical models for various turbulence models.

Fig. 6 illustrates the wind speed distribution along the axis on the various turbulent model. Inlet position of the diffuser in $X / D=0$ and the outlet position in $X / D=1.5$. The wind speed would increase when the wind come into the diffuser. The existence of low pressure inside diffuser leads to accelerating the wind speed. The geometrical shape of diffuser also affects this large increase.

\subsection{Accuracy of Validation Result}

This research uses numerical simulation with CFD rather than experimental. Therefore, we need to figure out the accuracy of the simulation results obtained by looking at a few parameters, such as mesh independence study, mesh quality, and mass imbalance.

\subsubsection{Study of Independence Mesh}

Mesh independence study was conducted to determine the number of mesh that will be used in validation and simulation research. The change of mesh independent in cells number is not a significant effect on the simulation results.

From the graph in Fig. 7, the value of the output of the speed $\left(U_{\max }\right)$ starts to level out when the number of the mesh are approximately 60000 cells. Therefore, the number of mesh that can be used to validate the simulation models are roughly 60000 cells.

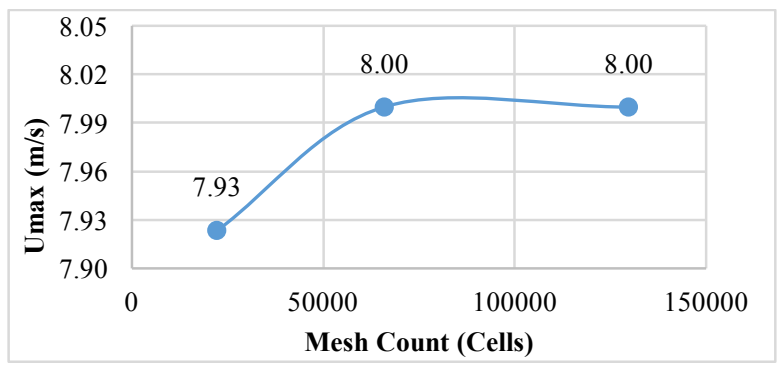

Fig. 7. The study of mesh independence for validation numerical model.

\subsubsection{Mesh Quality}

Mesh quality could be determined during the process of meshing by the parameters of skewness and orthogonal quality. Mesh with poor quality will lead to inaccurate simulation results and/or simulation requires a longer time to achieve convergence, even it may cause the simulation diverges. The value of skewness and orthogonal quality of research diffuser are 0.003 and 0.999 respectively. Thus, the mesh quality of simulation results for the validation implied in the excellent category.

\subsubsection{Convergence Criterion}

Convergence criteria determine the numerical convergence that would occur in the numerical solution. When the convergence is achieved, the numerical solution is unable to change again, due to the overall equation (mass, energy, momentum) on each of the cells has had fulfilled the convergence tolerance. The value of convergence criteria in the default state is $10^{-3}$. In this study, the value of the convergence criteria was changed to $10^{-5}$ for speed and continuity. The smaller the order is used, the error level in the settlement process will be smaller.

\subsubsection{Mass Imbalance}

Another important parameter to determine convergent simulation results is to examine the overall imbalance mass flow (mass imbalance), which is obtained from the difference between incoming mass flow and mass flow out. The appropriate value of mass imbalance should be less than $1 \%$ to meet the criteria of mass imbalance. The value of mass imbalance on the simulation results in the validation could be seen in Fig. 8. The magnitude of mass imbalance is $2.00 \times 10^{-7}$ or $<1 \%$.

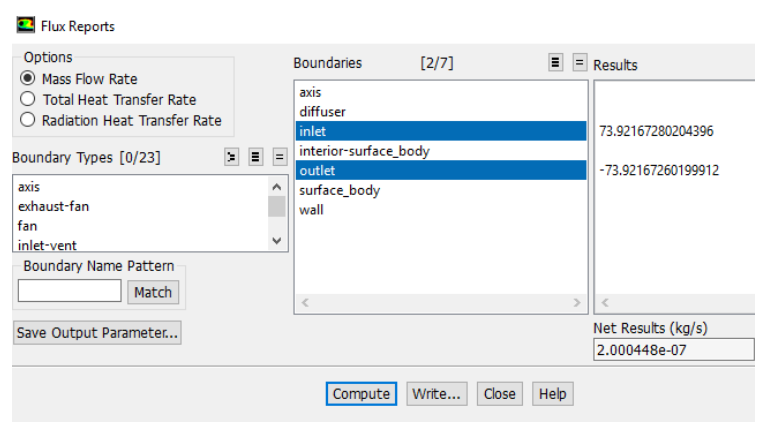

Fig. 8. The result of a mass imbalance in the validation of numerical models. 


\subsubsection{Multilevel Diffuser Simulation}

In this paper, the geometry design was used a multilevel diffuser with flange and an addition of inlet curvature. This study aims to present a simple numerical simulation using CFD to find the ratio of increase in speed from each geometrical model.

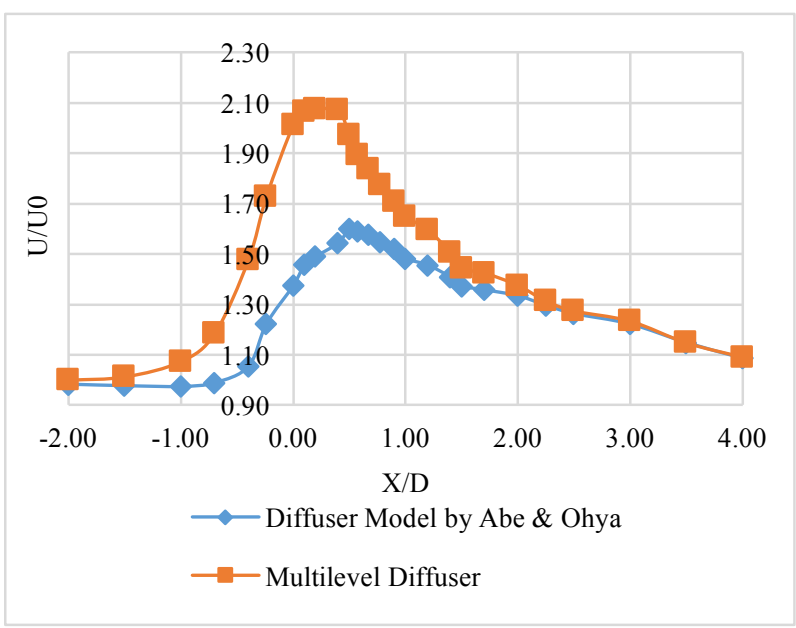

Fig. 9. Comparison of speed increment ratio distribution along on-axis for the multilevel diffuser model and diffuser model by Abe \& Ohya

Fig. 9 shows the comparison of speed increment ratio distribution along on-axis for the multilevel diffuser model and diffuser model by Abe \& Ohya. The ratio of the increase in speed generated by multilevel diffuser model is very significant, relative to diffuser model by Abe \& Ohya. The ratio of the increase in the maximum speed $\left(U_{\max } / U_{o}\right)$ reaches 2.08 times higher at $4 \mathrm{~m} / \mathrm{s}$ velocity inlet.

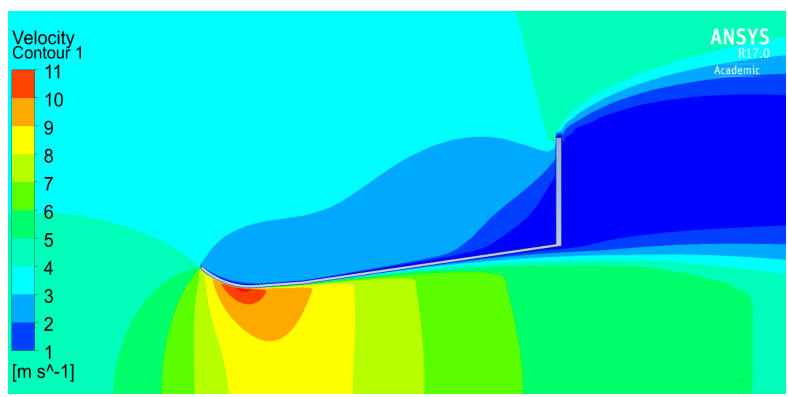

Fig. 10. Contour plot of the velocity of multilevel diffuser model.

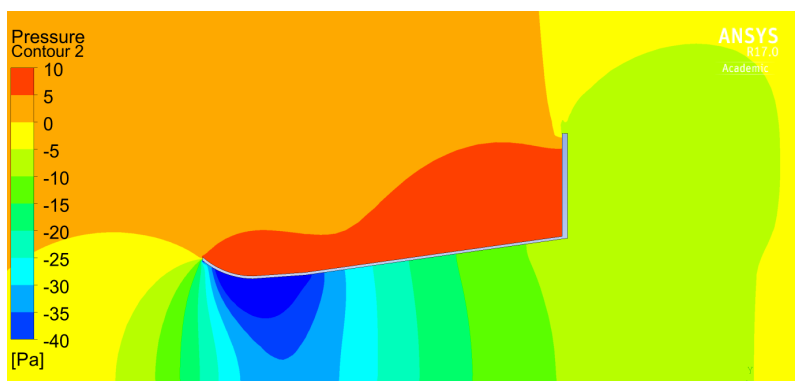

Fig. 11. Contour plot of the pressure of multilevel diffuser model.
Fig. 10 and Fig. 11 show the contour plot of velocity and contour plot of pressure from multilevel diffuser model are represented with its color degradation. Red indicates a high value, while blue indicates low value. In the diffuser, velocity increases while the pressure decreases. The increase in the highest speed is obtained at the lowest pressure. As seen in Fig. 10, there is a reddish orange color on the inside near the diffuser inlet showing the highest speed. While in Fig. 11, there is a wide dark blue on the inside near the diffuser inlet in which shows the lowest pressure.

Table 4. The distribution ratio of $U / U_{0}$ at some measurement points along the axis.

\begin{tabular}{|c|c|c|}
\hline \multirow{2}{*}{$\mathrm{X} / \mathrm{D}$} & \multicolumn{2}{|c|}{$U / U_{0}$} \\
\cline { 2 - 3 } & $\begin{array}{c}\text { Multilevel } \\
\text { Diffuser }\end{array}$ & $\begin{array}{c}\text { Diffuser Model } \\
\text { by Abe \& Ohya }\end{array}$ \\
\hline-2.00 & 1.00 & 0.98 \\
\hline-1.50 & 1.01 & 0.98 \\
\hline-1.00 & 1.07 & 0.97 \\
\hline-0.70 & 1.19 & 0.99 \\
\hline-0.40 & 1.48 & 1.05 \\
\hline-0.24 & 1.73 & 1.22 \\
\hline 0.00 & 2.01 & 1.38 \\
\hline 0.10 & 2.07 & 1.46 \\
\hline 0.16 & 2.08 & 1.49 \\
\hline 0.20 & 2.07 & 1.54 \\
\hline 0.40 & 1.97 & 1.60 \\
\hline 0.50 & 1.89 & 1.59 \\
\hline 0.58 & 1.84 & 1.58 \\
\hline 0.68 & 1.78 & 1.55 \\
\hline 0.78 & 1.71 & 1.52 \\
\hline 0.90 & 1.65 & 1.48 \\
\hline 1.00 & 1.60 & 1.46 \\
\hline 1.20 & 1.51 & 1.41 \\
\hline 1.40 & 1.44 & 1.37 \\
\hline 1.50 & 1.43 & 1.36 \\
\hline 1.70 & 1.38 & 1.33 \\
\hline 2.00 & 1.31 & 1.30 \\
\hline 2.25 & 1.27 & 1.26 \\
\hline 2.50 & 1.23 & 1.22 \\
\hline 3.00 & 1.15 & 1.15 \\
\hline 3.50 & 1.09 & 1.09 \\
\hline 4.00 & 1.05 & 0.95 \\
\hline & & \\
\hline
\end{tabular}

Table 4 illustrates the velocity distribution of the $\mathrm{X}$ axis at some point in the ratio of $X / D . \mathrm{D}$ is the diameter of the diffuser inlet. The highest speed ratio is in a position $X / D=0.16$. This position could be used as a reference position to locate the rotor on further research experiments.

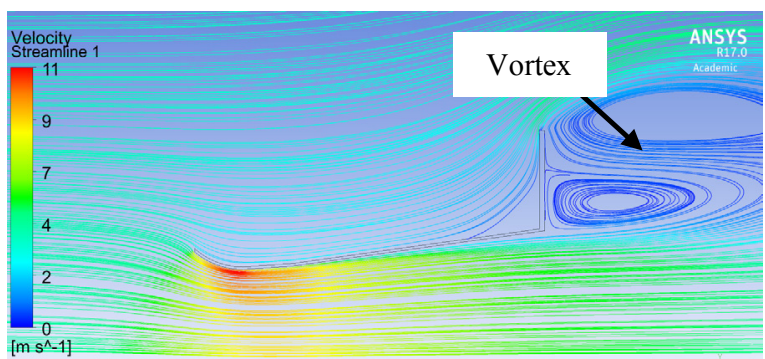

Fig. 12. Streamline of multilevel diffuser model. 


\subsection{Accuracy of Multilevel diffuser simulation}

\subsubsection{Study of Independence Mesh}

The study of independence mesh was conducted to determine the number of mesh that will be used in validation and simulation research. The change of mesh independent in cells number is not a significant effect on the simulation results. Therefore, the number of mesh that can be used to validate the simulation models are around 60000 cells.

\subsubsection{Mesh Quality}

The value of skewness and orthogonal quality are 0.016 and 0.999 respectively. Thus, the mesh quality of simulation results for the validation counted into the excellent category.

\subsubsection{Convergence Criterion}

In this research, the value of the convergence criteria was changed to $10^{\text {s }}$ for speed and continuity.

\subsubsection{Mass Imbalance}

The value of mass imbalance on the simulation results for multilevel diffuser model could be seen in Fig. 13. The magnitude of the imbalance is $2.73 \times 10^{-7}$ or $<1 \%$.



Fig. 13. Mass imbalance results in validation of numerical models

\section{Conclusion}

Numerical study of the design geometry of multilevel diffuser with flange and an addition of inlet curvature applied for a wind turbine has been performed using ANSYS 17.0 Student Version. In this study, a model turbulent of Spallart-Allmaras was used to solve the equations RANS. It is according to the results of the validation process that is able to approach the experimental results Abe \& Ohya (2004). The ratio of increase in the maximum speed $\left(U_{\max } / U_{o}\right)$ that could be reached by the multilevel diffuser model is 2.08 times higher at $4 \mathrm{~m} / \mathrm{s}$ velocity inlet and the recommendation position to put the rotor of wind turbine is in $X / D=0.16$.

The results of testing the accuracy of the simulation results refer to the study of mesh independence, mesh quality and mass imbalance shows that the CFD simulation results in research of multilevel diffuser wind turbines are accurate and acceptable. However, this research mainly relying on numerical simulation and so does need a further experiment to be tested and verified in the real condition.

\section{References}

[1] K.I. Abe, Y. Ohya, J. Wind Eng. Ind. Aerod 92, 315 330 (2004)

[2] Y. Ohya, T. Karasudani, A. Sakurai, K.I. Abe, M. Inoue, J. Wind Eng. Ind. Aerod 96, 524-539 (2008)

[3] Y. Ohya, T. Karasudani, Energies 3, 634-649, (2010)

[4] D. Wahyu, Purwanto,. Geometrical Variation Analysis of Diffuser Performance on Diffuser Augmented Wind Turbine. ITS. Surabaya.

[5] T.S. Kannan, S.A. Mutasher, Y.H.K. Lau, (2013). Design and Flow Velocity Simulation of Diffuser Augmented Wind Turbine Using CFD, 8(4), 372384. (2011)

[6] A. Tito, H. Wibowo, R.A. Wahyuono,. Numerical Study of Geometrical Performance and Diffuser Design for Improving the Performance of Diffuser Augmented Wind Turbine, 14(2), 90-96. doi:10.9744/jtm.14.2.90-96. (2013)

[7] T. Jiyuan, G.H. Yeoh, C. Liu, Computational Fluid Dynamics: A Practical Approach (Elsevier, Oxford, 2008) 